\title{
Serum Transferrin of Pregnant Mothers Related to Birth Weight of their Infants
}

\author{
T. N. MALETNLEMA， T. P. EDDY
}

British Medical fournal, 1972, 3, 386-387

\section{Summary}

In a study of 81 pregnant mothers and their newborn infants the maternal serum transferrin concentration at about 24 weeks of gestation was shown to have a low but significant correlation with infant birth weight $(r=0.33 ; \quad P<0.01)$. Maternal undernutrition is suggested as a possible cause of low serum transferrin levels.

\section{Introduction}

The extent to which fetal malnutrition resulting from maternal malnutrition may affect the outcome of pregnancy has been clearly shown in animals (Dobbing, 1963, 1970, 1971; Zamenhof et al., 1968; Chase, 1971; Stewart, 1971). In man, however, only a few indices of maternal nutritional status, such as height and weight gain during pregnancy (Hytten and Leitch, 1964; Beilly et al., 1945), have shown a consistent correlation with the birth weight of the infant. Other workers (Klein, 1946) have not found a significant correlation between maternal weight gain during pregnancy and birth weight.

The study reported here was conducted in Kisarawe, a rural area of Tanzania about $80 \mathrm{~km}$ from the capital city, Dar es Salaam. Burgess et al. (1969) showed that among preschool children in this area the incidence of protein-calorie deficiency is high, and Maletnlema et al. (1972), in a dietary survey conducted in the same area, found that adults also suffer from undernutrition. All mothers included in this study were the wives of full-time or part-time peasant farmers with a yearly income below the national average of $\$ 80$. To attend the clinic mothers had to walk up to $6 \mathrm{~km}$.

The main aim of the study was to identify malnourished mothers by their anthropometric or biochemical characteristics or both, and to study the relation between these data and the birth weight of their children.

\section{Methods}

After the study procedure had been discussed with village heads pregnant mothers were asked to report to a clinic as early as possible. All mothers reporting at or before 24 weeks of gestation were registered for this study; the rest were given the usual antenatal care. Gestational age was determined from the date of the last menstrual period or from fundal size. Every fortnight, when the mothers were examined clinically, anthropometric measurements were taken. These included height (on the first visit only), weight, triceps skinfold thickness, and mid-arm and mid-thigh circumferences. Venous blood samples taken on the first visit were analysed for haemoglobin content (cyanmethaemoglobin method-King and Gilchrist, 1947), serum total protein and albumin (Biuret method-Gornall et al., 1949), and serum transferrin (Immunodiffusion method-Mancini et al., 1965). At or within 20 hours after parturition the anthropometric measurements

Nutrition Unit, Ministry of Health and Social Welfare, Tanzania T. N. MALETNLEMA, M.B., cH.B., Specialist in Human Nutrition

Department of Human Nutrition, London School of Hygiene and Tropical Medicine, London W.C.1.

T. P. EDDY, M.R.C.S., L.R.C.P., M.F.C.M., Senior Lecturer

were repeated on the mothers and the infants were weighed and examined clinically. A second maternal blood sample was obtained for transferrin estimation at full term or within 20 hours of parturition whenever possible, but owing to lack of staff this could not always be done. Thus only 47 of the 83 mothers who were registered for the study had the second blood sample taken at the right time. Two infants showing signs of prematurity (thin, shiny skin; lack of pigment; short, thin nails; and low birth weights of 1,780 and $1,280 \mathrm{~g}$ respectively) were excluded, as were their mothers, one of whom developed oedema and toxaemia of pregnancy at 36 weeks.

The changes in anthropometric data reported in this paper were those occurring during the third trimester. Owing to the difficulty of determining the gestational age, what we took to be the beginning of the third trimester may have been anything from the 22 nd to the 26th week.

\section{Results}

We have divided the 81 neonates into three arbitrarily defined groups-large, medium, and small-according to their weight. The characteristics of mothers giving birth to infants in each group are shown in Table $I$. Mothers of large infants tended to be taller and gained more weight than those of small

TABLE I-Characteristics of Mothers Related to Size of Infants (Changes shown occurred during Third Trimester)

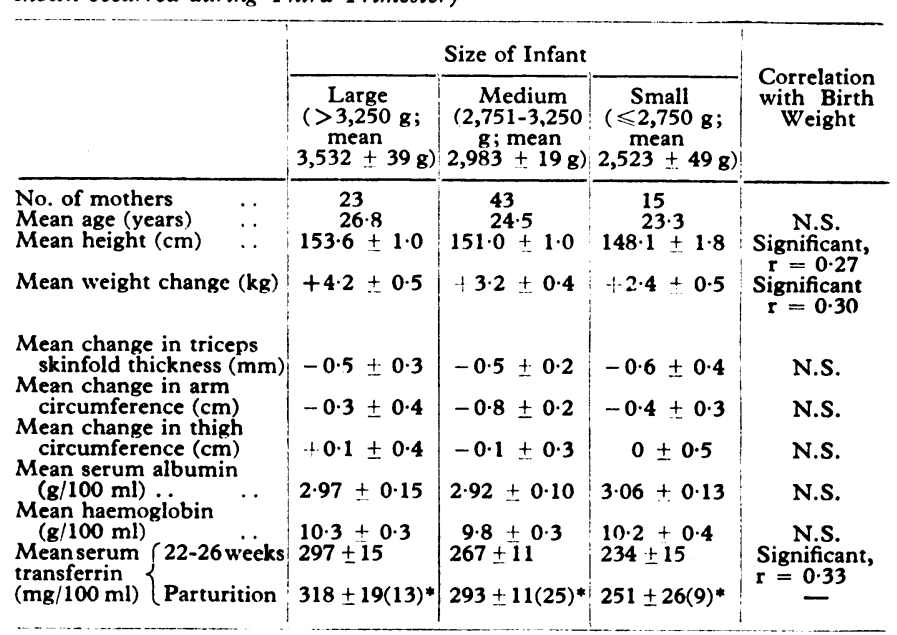

* Figures in parentheses are numbers of mothers studied.

N.S. = Not significant.

infants. The mean weight gain of $3.2 \mathrm{~kg}$ for the combined groups was only about half of that reported in Aberdeen women by Hytten and Leitch (1964). A few mothers lost weight and a few gained over $10 \mathrm{~kg}$, but the majority showed very slight change. As with the Aberdeen mothers, triceps skinfold thickness fell as pregnancy advanced; the mid-arm and mid-thigh circumferences also fell, and the three groups of mothers behaved very similarly in these respects.

At the time of the first blood sample maternal serum albumin and haemoglobin levels were much the same in all three groups; serum transferrin values were highest in the mothers of large infants, intermediate in the medium-size group, and lowest in the mothers of small infants. At the end of pregnancy the transferrin levels had risen by almost the same amount in all three groups. When the weight limits of the three groups of infants are rearranged to produce groups 
of equal size the distribution of material serum transferrin levels at the start of the thind trimester in these groups can be compared (Table II). The coefficient of linear correlation ( $r$ ) between serum transferrin and infant size was $0.33(P<0.01)$.

TABLE II-Frequency Distribution of Maternal Serum Transferrin according to Size of the 81 Infants.

\begin{tabular}{|c|c|c|c|c|}
\hline \multirow{2}{*}{$\begin{array}{c}\text { Maternal Serum } \\
\text { Transferrin } \\
(\mathrm{mg} / 100 \mathrm{ml})\end{array}$} & \multicolumn{3}{|c|}{ Size of Infant } & \multirow[b]{2}{*}{ Total } \\
\hline & $\begin{array}{c}\text { Large } \\
(>3,240 \mathrm{~g})\end{array}$ & $\begin{array}{c}\text { Medium } \\
(2,900-3,240 \mathrm{~g})\end{array}$ & $\begin{array}{c}\text { Small } \\
(<2,900 \text { g })\end{array}$ & \\
\hline $\begin{aligned} 291-445 & \ldots \\
251-290 & \ldots \\
50-250 & \ldots\end{aligned}$ & $\begin{array}{r}13 \\
10 \\
4\end{array}$ & $\begin{array}{r}11 \\
8 \\
8\end{array}$ & $\begin{array}{l}1 \\
12 \\
14\end{array}$ & $\begin{array}{l}25 \\
30 \\
26\end{array}$ \\
\hline Total & 27 & 27 & 27 & 81 \\
\hline
\end{tabular}

- For the purpose of this calculation the infants have been rearranged into three equal groups.

$x_{i}^{2}=13.4, P<0.01 \quad$ Yates's correction applied).

\section{Discussion}

These results show that a mother's height, weight gain during pregnancy, and serum transferrin concentration are related to the weight of her infant at birth. Small infants at birth have been shown to have a higher mortality than their heavier mates (Baumgartner, 1962; Bergner and Susser, 1970). However, it is almost impossible to draw a clear line between normal and abnormal birth weights. The World Health Organization minimum normal birth weight of $2,500 \mathrm{~g}$ is probably not applicable to the group studied here (Ebrahim and D'Sa, 1966). Owing to the many factors acting on birth weight one cannot say that a birth weight of $2,600 \mathrm{~g}$ from a tall mother with malnutrition and malaria is normal simply because the weight is above the W.H.O. limit, for the infant could be otherwise subnormal. Therefore it is wiser in our opinion to classify newborn infants simply as light or heavy.

McFarlane et al. (1969), working with a Nigerian population similar to that of Tanzania, showed that the serum transferrin level was low in children suffering from protein-calorie deficiency. In our study low maternal serum transferrin was significantly related to low birth weight. We have already pointed out the prevalence of adult undernutrition in the population studied. Without dietary information we cannot go further than to suggest maternal malnutrition as a cause of low serum transferrin.
The serum albumin level was very low in some mothers and normal in others, but this did not seem to be related to the transferrin level or to infant birth weight. In children Waterlow et al. (1960) noted that individual values of serum proteins (total, albumin, and globulin) were not particularly useful in detecting malnutrition, Transferrin may therefore be a more sensitive tool in the diagnosis of malnutrition even in adults. Skinfold thicknesses and mid-arm and mid-thigh circumferences varied widely under the influence of many factors which we could not clearly define.

As pointed out by McFarlane, the serum transferrin level is easy to determine, even in the field, and the cost per person is not high. For mothers, however, more work needs to be done to study the relation of the transferrin level to nutritional status and to determine the best time for its measurement, since it rises as pregnancy advances.

This study was financed by the Tanzania Government with the help of the World Health Organization.

\section{References}

Baumgartner, L. (1962). Bulletin of the World Health Organization, 26, 175. Beilly, J. S., and Kurland, I. I. (1945). American fournal of Obstetrics and Gynecology, 50, 202

Bergner, L., and Susser, M. W. (1970). Paediatrics, 46, 946.

Burgess, L. J., Maletnlema, T. N., and Burgess, A. (1969). Tropical and Geographical Medicine, 21, 39.

Chase, H. P. (1971). In Proceedings of XIII International Congress of Paediatrics-Vienna 1971, vol. II, No. 1 Vienna, Medizinischen Akademie.

Dobbing, J. (1963). Proceedings of the Royal Society of London, Series B 159,503 .

Dobbing, J. (1970). American fournal of Diseases of Children, 120, 411.

Dobbing, J. (1971). In Proceedings of XIII International Congress of Paediatrics -Vienna 1971, vol. II, No. 1. Vienna, Medizinischen Akademie.

Ebrahim, G. J., and D'Sa, A. (1966). Fournal of Tropical Pediatrics and African Child Health, 12, 55.

Gornall, A. G., Bardawill, C. J., and David, M. M. (1949). Fournal of Biological Chemistry, 177, 751 .

Hytten, F. E., and Leitch, I. (1964). Physiology of Human Pregnancy. Oxford, Blackwell Scientific.

King, E. J., and Gilchrist, M. (1947). Lancet, 2, 201.

Klein, J (1946). American fournal of Obstetrics and Gynecology, 52, 574.

McFarlane, H., et al. (1969). Lancet, 1, 392

Maletnlema, T. N., Mhombolage, R., and Ngowi, G. E. (1972). Tanzanio Notes and Records. No. 73.

Mancini, G., Carbonara, A. O., and Heremans, J. F. (1965). Immunochemistry, 2, 235.

Stewart, R. J. C. (1971). Van den Berghs and Jurgens Nutrition Award Paper 1971.

Waterlow, J. C., Cravioto, J., and Stephen, J. M. (1960). Advances in Protein Chemistry, 15, 131 .

Zamenhof, S., van Marthens, E., and Margolis, F. L. (1968). Science, 160, 322 .

\title{
Rheumatic Fever and Rheumatic Heart Disease in Barbados: Detection and Prophylaxis
}

\author{
T. A. HASSELL， SONIA RENWICK， K. L. STUART
}

British Medical fournal, 1972, 3, 387-389

\section{Summary}

The objectives of this study were to improve our methods of secondary prophylaxis of rheumatic fever and rheumatic heart disease in Barbados, to estimate the overall

\section{Queen Elizabeth Hospital, Barbados}

T. A. HASSELL, M.B., M.R.C.P., Consultant Physician

Ministry of Health, Barbados

SONIA RENWICK, M.B., B.S., Medical Officer

University of the West Indies, Jamaica

K. L. STUART, M.D., F.R.C.P., Professor of Medicine prevalence of these diseases and the relative load imposed by them on available health services, and to measure the yield, feasibility, and efiectiveness of mass programmes for the detection and prophylactic management of rheumatic heart disease in schoolchildren.

Improved methods of surveillance and follow-up resulted in $97 \%$ adherence to therapy by patients on prophylactic penicillin. Thirty-four children, 27 with a first attack, were admitted with acute rheumatic fever, representing a $7 \%$ occupancy of children's medical beds during the 12-month period of the study. Out of a possible 3,942 schoolchildren aged 5-11 years, 3,882 (98\%) were screened for rheumatic heart disease. Four cases (about 1 per 1,000) were discovered. 